\title{
Testes para a seleção de populações de cenoura visando ao vigor e à longevidade das sementes
}

\author{
Tests for the selection of carrot populations to order the vigor and longevity of seeds
}

\author{
Cibele Chalita Martins ${ }^{\mathrm{I}}$ Norberto da Silva ${ }^{\text {II }}$ Carla Gomes Machado ${ }^{\text {III }}$
}

RESUMO

Populações de cenoura com sementes de maior qualidade fisiológica e potencial de armazenamento são de interesse para as empresas de sementes e horticultores. Assim, verificouse a eficiência de alguns testes para a seleção de populações de cenoura com maior vigor e longevidade das sementes. Sementes de 50 progênies de meio-irmãos de cenoura tipo Brasília foram avaliadas quanto à massa de cem sementes, primeira contagem de germinação, germinação, dormência, envelhecimento acelerado com água e com solução saturada de $\mathrm{NaCl}$. As sementes foram

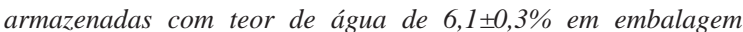
hermética nas temperaturas de 15 e $25^{\circ} \mathrm{C}$ por 12 meses e a germinação foi avaliada trimestralmente. Os dados experimentais foram avaliados quanto à variância e correlações fenotípicas, genotípicas e ambientais; herdabilidade; coeficiente de variação genética e ganho por seleção. A seleção baseada na massa não deve ser utilizada, pois aumentaria a ocorrência de dormência nas sementes da geração seguinte. Os testes da primeira contagem, de germinação e de envelhecimento acelerado com água ou solução salina saturada podem ser utilizados para selecionar populações de cenoura com sementes de maior vigor e longevidade. O ganho genético estimado com a seleção para a germinação após 12 meses de armazenamento a $25^{\circ} \mathrm{C}$ foi de $14 \%$.

Palavras-chave: Daucus carota, melhoramento, envelhecimento acelerado, testes de vigor.

\section{ABSTRACT}

Populations of carrot seeds with superior physiological quality and storage potential are of interest to seed companies and growers. Thus, we verified the efficiency of some tests for the selection of carrot populations with greater vigor and longevity of seeds. Seeds of 50 carrots progenies of different halfbrothers from Brasilia cultivar were evaluated for the mass of one hundred seeds, the first count, germination, dormancy, accelerated aging with water and saturated $\mathrm{NaCl}$ solution. The seeds were stored at moisture contents of $6.1 \pm 0.3 \%$ in hermetic packaging at temperatures of 15 and $25^{\circ} \mathrm{C}$ for 12 months and germination was evaluated quarterly. The experimental data were evaluated for variance and phenotypic, genotypic and environmental heritability, coefficient of variation and genetic gain from selection. Selection based on the mass should not be used because it would increase the occurrence of dormancy in seeds of the next generation. The test of the first count, germination and accelerated aging in water or saline solution saturated may be used to select populations of carrot seeds of higher vigor and longevity. The estimated gain genetic selection for germination after 12 months storage at $25^{\circ} \mathrm{C}$ was $14 \%$

Key words: Daucus carota, breeding, accelerated aging, vigor tests.

\section{INTRODUÇÃO}

A disponibilidade de populações de cenoura com sementes de maior vigor e longevidade é do interesse do produtor e das empresas de sementes, considerando que as disponíveis no mercado apresentam baixo potencial de armazenamento (HONG et al., 2005; VIEIRA et al., 2005; PEREIRA et al., 2007).

O período de armazenamento das sementes de hortaliças é relativamente longo, principalmente para espécies que têm grande variação no volume de produção por safra. Essas espécies produzem mais em determinados anos do que em outros, enquanto a demanda por sementes no mercado é estável. É prática

IDepartamento de Produção Vegetal, Faculdade de Ciências Agrárias e Veterinárias, Universidade Estadual Paulista (UNESP), 14884-900, Jaboticabal, SP, Brasil. E-mail: cibele@fcav.unesp.br. Autor para correspondência.

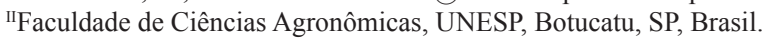

"IIUniversidade Federal de Goiás (UFG), Campus Jataí, Unidade Jatobá, Jataí, GO, Brasil. 
comum das empresas o armazenamento das sementes em ambiente sob condições controladas de baixa temperatura e umidade relativa para a conservação da qualidade fisiológica. As sementes de hortaliças, por apresentarem menores quantidades de reservas que as de grandes culturas, possuem maior propensão à deterioração (FREITAS, 2009).

Para estabelecer políticas de armazenamento, comercialização e controle de qualidade, as empresas produtoras de sementes têm utilizado os resultados de testes de vigor em conjunto com o teste de germinação para a tomada de decisões, em especial, na comparação de lotes. Alguns testes de vigor, como o envelhecimento acelerado com água ou com o uso de solução saturada de $\mathrm{NaCl}$, apresentam eficiência na avaliação da qualidade fisiológica de sementes de cenoura e, adicionalmente, são capazes de identificar lotes com maior potencial de armazenamento (ANDRADE et al., 1995; RODO et al., 2000).

No entanto, os testes de vigor também podem ser usados em programas de melhoramento genético, para a comparação e seleção de linhagens, cultivares e híbridos com sementes de qualidade superior. A longevidade e o vigor da semente de cenoura e de outras olerícolas está subordinada principalmente a fatores genéticos e, assim, existem diferenças entre gêneros, espécies e algumas vezes, entre genótipos (FREITAS, 2009; SILVA et al., 2011; MARTINS et al., 2013).

Estudos com altos valores de herdabilidade e variabilidade genética entre progênies de meioirmãos de cenoura indicaram que a aplicação de métodos de melhoramento simples, combinados com métodos de seleção, tendo por base a teoria de índices, poderiam ser utilizados para a melhoria da qualidade fisiológica das sementes (VIEIRA et al., 2005).

Assim, o objetivo do trabalho foi verificar a eficiência de algumas determinações e testes laboratoriais para a seleção de populações de cenoura com maior vigor e longevidade das sementes.

\section{MATERIAL E MÉTODOS}

No trabalho, foram avaliadas 50 populações de meio-irmãos oriundas de uma população de cenoura tipo Brasília, pertencentes a um programa de melhoramento realizado pela área de melhoramento genético da FCA-UNESP-Câmpus de Botucatu, SP. Quando todas as plantas de cenoura apresentavamse secas no campo, com as umbelas formadas e antes da dispersão, foram cortadas, acondicionadas individualmente em sacos de papel unifoliados e transferidas para galpão ventilado $\left(20-35^{\circ} \mathrm{C}\right.$ e 30 $60 \% \mathrm{UR}$ ) por aproximadamente 20 dias. As progênies foram obtidas a partir da mistura das sementes de todas as umbelas de plantas individuais.

As sementes de cada progênie foram submetidas à limpeza e classificação em peneiras de malha metálica, utilizando-se somente sementes com tamanho entre 1,41 e 2,00mm. Após o beneficiamento, foi determinado o teor de água das sementes, que deveria situar-se abaixo de $7 \%$, recomendado para o armazenamento de sementes de cenoura em embalagem impermeável (FREITAS, 2009). Quando necessário, a secagem das sementes foi realizada em dessecador contendo sílica-gel ativada (35\%UR), na temperatura de $20^{\circ} \mathrm{C}$ (HONG et al., 2005). O tamanho e o teor de água inicial das sementes foram padronizados para evitar seus efeitos sobre o vigor e os testes de avaliação de qualidade (MARCOS FILHO \& NOVEMBRE, 2009; SANTOS et al., 2010).

A embalagem hermética foi composta de sacos multifoliados impermeáveis, utilizados no armazenamento e comercialização de sementes certificadas de hortaliças, apresentando a seguinte composição da parte externa para a interna: poliester $\left(17 \mathrm{~g} \mathrm{~m}^{2-1}\right)$, tintas $\left(2 \mathrm{~g} \mathrm{~m}^{-2}\right)$, fixador tipo primer $(0,015 \mathrm{~g}$ $\left.\mathrm{m}^{-2}\right)$, polietileno extrusado $\left(15 \mathrm{~g} \mathrm{~m}^{-2}\right)$, alumínio $(8 \mu$ de espessura, 21,6 $\left.\mathrm{g} \mathrm{m}^{-2}\right)$, adesivo $\left(2 \mathrm{~g} \mathrm{~m}^{-2}\right)$, filme de poliestireno $\left(50 \mathrm{~g} \mathrm{~m}^{-2}\right)$ e gramatura total de $107,6 \mathrm{~g} \mathrm{~m}^{-2}$.

Dentro dessa embalagem, as sementes foram armazenadas nas temperaturas de 15 e $25^{\circ} \mathrm{C}$, que são, respectivamente, a temperatura adotada pelas empresas produtoras de sementes de olerícolas para o armazenamento de sementes certificadas e a temperatura próxima a do ambiente. A qualidade inicial das sementes foi avaliada por meio de todos os testes descritos a seguir e, trimestralmente, até 12 meses de armazenamento, por meio do teste de germinação.

A qualidade das sementes das progênies foi avaliada por meio das seguintes determinações e testes: massa de cem sementes - pesando-se quatro subamostras de 100 sementes por progênie em balança com 0,0001g de precisão; germinação realizado com quatro subamostras de 50 sementes, semeadas sobre duas folhas de papel mata-borrão, umedecidas com 2,5 vezes o peso do papel em água, em caixas plásticas transparentes $(11 \times 11 \times 3,5 \mathrm{~cm})$, na temperatura de $20^{\circ} \mathrm{C}$, e contagens efetuadas no sétimo e no 14ํㅜ dia após a semeadura (BRASIL, 2009); primeira contagem de germinação - contabilizando- 
se as plântulas normais no sétimo dia após a semeadura do teste de germinação; envelhecimento acelerado com água - conduzido com $2 \mathrm{~g}$ de sementes sobre tela em caixa plástica transparente $(11 \times 11 \times 3,5 \mathrm{~cm})$, contendo $40 \mathrm{~mL}$ de água, mantida a $41^{\circ} \mathrm{C}(100 \% \mathrm{UR})$ por 72 horas (ANDRADE et al., 1995; RODO et al., 2000), seguindo-se da avaliação da germinação com o mesmo procedimento do teste de germinação com contagem no sétimo dia; envelhecimento acelerado com solução salina saturada - utilizando o mesmo procedimento do item anterior, sendo a água substituída por uma solução saturada de $\mathrm{NaCl}$ (40\%), de modo a obter um ambiente com $76 \%$ de UR do ar (JIANHUA \& McDONALD, 1997; RODO et al., 2000); teor de água das sementes - foi determinado antes e após o envelhecimento acelerado com água e com solução salina saturada, utilizando-se duas subamostras para cada lote, adotando-se o método da estufa a alta

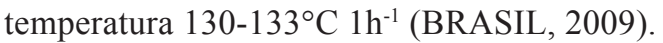

Os dados experimentais foram submetidos à análise de variância e covariância, utilizando-se o aplicativo Genes-UFV (CRUZ, 1997) e estimados os parâmetros: variância fenotípica e genotípica entre médias de progênies; variância ambiental média; herdabilidade, no sentido amplo, baseada na média das parcelas; coeficiente de variação genética; correlações fenotípicas, ambientais e genéticas; ganho por seleção (VIEIRA et al., 2005).

\section{RESULTADOS E DISCUSSÃO}

O teor de água inicial das sementes das progênies foi de $6,1 \pm 0,3 \%$, valor situado dentro dos limites recomendados para o acondicionamento de sementes de cenoura e outras hortaliças em embalagens herméticas (FREITAS, 2009; CARVALHO \& NAKAGAWA, 2012). Em sementes ortodoxas, como as de cenoura, a deterioração durante o armazenamento é maior em sementes com maior teor de água e, caso as progênies fossem armazenadas com diferentes teores de água, isso iria afetar a longevidade e comprometer os resultados.

Adicionalmente, a uniformidade do teor de água inicial das sementes é um fator primordial para a padronização dos testes e determinações a serem realizadas e, no caso do teste de envelhecimento, é conveniente a comparação de amostras que apresentem teor de água inicial com diferenças menores que $2 \%$ para não comprometer os resultados, devido às diferenças na velocidade de umedecimento e na deterioração das sementes durante o envelhecimento (MARCOS FILHO \& NOVEMBRE, 2009).
O teor de água das sementes das progênies após o envelhecimento acelerado com água e com solução salina foi de, respectivamente, $34,8 \pm 6,2 \%$ e $10,2 \pm 2,6 \%$. Assim, constata-se que o teor de água das sementes, após os testes, foi diferente entre as progênies, tendo sido mais discrepante para o teste sem sal.

O teor de água das sementes após o envelhecimento é um dos principais indicadores da uniformidade das condições do teste, e variações de 3 a 4\% entre lotes são consideradas toleráveis (MARCOS FILHO \& NOVEMBRE, 2009). Os teores de água das sementes de cenoura após os testes de envelhecimento acelerado mostraram diferenças superiores a esses valores, mas deve-se considerar que, nesta pesquisa, as comparações foram entre sementes de progênies (geneticamente diferentes) e não entre lotes (geneticamente iguais).

Também, SPÍNOLA et al. (1998) e RODO et al. (2000), trabalhando com sementes de cenoura, constataram elevação acentuada no teor de água após o envelhecimento acelerado, com variações entre 7,2 e 9,2 pontos percentuais. Esse é um dos problemas que se procura sanar com a utilização de solução salina no envelhecimento acelerado. As sementes submetidas ao teste de envelhecimento acelerado modificado (em solução salina saturada de $\mathrm{NaCl}$ ) absorveram quantidade de água menor do que aquelas submetidas ao teste normal (utilizando somente água), isso porque a solução salina controla a umidade relativa do ar, mantendo-a em torno de $76 \%$, como indica a literatura (JIANHUA \& McDONALD, 1997).

Os resultados da análise de variância e as estimativas de herdabilidade dos caracteres do peso de cem sementes, porcentagem de germinação, dormência e vigor de sementes, avaliados pelos testes de primeira contagem de germinação, envelhecimento acelerado com água e com solução salina e germinação após armazenamento das sementes na temperatura de $15^{\circ} \mathrm{C}$ e $25^{\circ} \mathrm{C}$ por 12 meses são apresentados na tabela 1 . Os dados de germinação após o armazenamento das sementes na temperatura de $15^{\circ} \mathrm{C}$ e $25^{\circ} \mathrm{C}$ nos períodos de tempo intermediários de 3, 6 e 9 meses apresentaram valores numéricos e estatísticos de igual magnitude que os obtidos aos 12 meses e não foram apresentados nas tabelas.

A avaliação dos caracteres analisados foi realizada com precisão experimental, principalmente, para peso de cem sementes, cujo coeficiente de variação foi de $2,59 \%$. Esse valor foi inferior ao de $6,4 \%$ e $3,8 \%$, respectivamente, obtidos por VIEIRA et al. (2005) e PEREIRA et al. (2007) também para 
Tabela 1 - Análises de variâncias e estimativa dos parâmetros genéticos para peso de cem sementes em gramas (P), porcentagem de germinação (G), dormência (D) e vigor de sementes, avaliados pelos testes de primeira contagem de germinação (PC), envelhecimento acelerado com água (EAA) e com solução salina (EAS), porcentagem de germinação após armazenamento por 12 meses a $15^{\circ} \mathrm{C}\left(\mathrm{G} 15^{\circ} \mathrm{C}\right)$ e $25^{\circ} \mathrm{C}\left(\mathrm{G} 25^{\circ} \mathrm{C}\right)$ avaliados em 50 progênies de meio-irmãos de cenoura.

\begin{tabular}{|c|c|c|c|c|c|c|c|c|c|}
\hline \multirow{2}{*}{ Fontes de Variação } & \multirow{2}{*}{ GL } & \multicolumn{8}{|c|}{ Quadrado Médio----- } \\
\hline & & $\mathrm{P}$ & G & $\mathrm{D}$ & $\mathrm{PC}$ & EAA & EAS & $\mathrm{G} 15^{\circ} \mathrm{C}$ & $\mathrm{G} 25^{\circ} \mathrm{C}$ \\
\hline Blocos & 3 & 0,00001 & 84,8 & 29,6 & 122,1 & 52,6 & 3,6 & 25,4 & 5,8 \\
\hline Progênies & 49 & $0,00423 * *$ & $621,8 * *$ & $196,5^{* *}$ & $737,2 * *$ & $585,6^{* *}$ & $640,3^{* *}$ & $809,9 * *$ & $808,5^{* *}$ \\
\hline Resíduo & 150 & 0,00001 & 53,1 & 34,4 & 52,5 & 56,6 & 44,2 & 44,4 & 55,4 \\
\hline Média & & 0,14576 & 68,9 & 10,8 & 65,1 & 51,7 & 64,4 & 63,1 & 64,1 \\
\hline $\mathrm{CVe}$ & & 2,59306 & 10,6 & 54,5 & 11,1 & 12,8 & 10,3 & 10,6 & 11,3 \\
\hline$h^{2}$ & & 99,66320 & 91,5 & 82,5 & 92,9 & 90,4 & 93,1 & 94,5 & 93,2 \\
\hline $\mathrm{CVg}$ & & 22,27700 & 17,3 & 59,2 & 20,1 & 19,6 & 19,0 & 21,9 & 20,8 \\
\hline $\mathrm{CVg} / \mathrm{CVe}$ & & 8,59100 & 1,6 & 1,1 & 1,8 & 1,5 & 1,8 & 2,1 & 1,8 \\
\hline
\end{tabular}

** Significativo a $1 \%$ de probabilidade pelo teste $\mathrm{F}$.

GL- graus de liberdade, CVe- Coeficiente de variação, $h^{2}$-Herdabilidade, CVg-Coeficiente de variação genética.

meio-irmãos de cenoura tipo Brasília. Isso pode ser atribuído à padronização do tamanho das sementes das diferentes progênies usadas neste experimento (entre 1,41 e $2,00 \mathrm{~mm}$ ).

As progênies de meio-irmãos apresentaram diferenças significativas em todos os caracteres avaliados (Tabela 1), inclusive para a germinação após os períodos de armazenamento de 3,6 e 9 meses a $15^{\circ} \mathrm{C}$ e $25^{\circ} \mathrm{C}$. Os altos valores dos coeficientes de variabilidade genética entre progênies para os caracteres em estudo sugerem que há possibilidade de ganhos expressivos no processo de seleção para todos os parâmetros estudados e que estão relacionados à qualidade de sementes, tais como: peso, germinação, dormência, vigor e longevidade. Também as estimativas dos parâmetros de herdabilidade e da relação entre os coeficientes de variação genética e experimental refletem uma situação muito favorável à seleção. Coeficientes de herdabilidade acima de $82,5 \%$ e, em média, de $92,2 \%$ possibilitam predizer que o acréscimo na média dos caracteres selecionados serão quase equivalentes ao diferencial de seleção imposto sobre aquele caráter. Resultados igualmente promissores foram constatados para peso, germinação e primeira contagem da germinação de sementes de meio-irmãos de cenoura tipo Brasília, por VIEIRA et al. (2005).

A grande disponibilidade de variabilidade genética para os caracteres estudados é um reflexo da pequena importância que tem sido dada ao aprimoramento da qualidade das sementes nos programas de melhoramento genético de cenoura, que somente tem buscado aprimorar caracteres de planta e raiz (SILVA et al., 2011). O alto grau de complexidade da maioria dos caracteres quantitativos, em termos de quantidade de genes e ação gênica, faz com que possam estar, de certa maneira, relacionados. Estudos dessas associações, que podem ser geradas pela pleiotropia, ligação gênica e pelo ambiente, são fundamentais para avaliar a magnitude e sentido da alteração num caráter quando o outro correlacionado está sob seleção.

Todos os caracteres avaliados apresentaram correlações genotípicas e fenotípicas positivas e altamente significativas, exceto na correlação entre o peso de 100 sementes e o teste de vigor da primeira contagem de germinação (Tabela 2).

A dormência também não apresentou correlação de qualquer tipo com os outros caracteres, exceto com o peso de sementes, a germinação e o teste de vigor da primeira contagem de germinação, realizado antes do armazenamento das sementes.

A correlação genética positiva entre o peso das sementes e a dormência indica que a seleção baseada em peso das sementes aumentaria a ocorrência de dormência na geração seguinte. A dormência das sementes causa atraso e desuniformidade na germinação, provocando falhas no fechamento do campo. Esse fato explica a correlação significativa e negativa entre a dormência e os testes da primeira contagem (baseado na velocidade de germinação) e de germinação. Assim, é uma característica que deve ser eliminada nos programas de melhoramento genético. Adicionalmente, a dormência das sementes é superada com o passar do tempo (CARVALHO \& 
Tabela 2 - Correlações genotípicas, fenotípicas e ambientais entre os caracteres peso de cem sementes, porcentagem de germinação, de dormência e vigor de sementes avaliados pelos testes de primeira contagem de germinação, envelhecimento acelerado (EA) com água e com solução salina, de germinação após armazenamento das sementes por 12 meses na temperatura de $15^{\circ} \mathrm{C}$ e $25^{\circ} \mathrm{C}$, avaliados em 50 progênies de meio-irmãos de cenoura.

\begin{tabular}{|c|c|c|c|}
\hline \multirow{2}{*}{ Caracteres } & \multirow[b]{2}{*}{ Genotípicas } & \multirow[b]{2}{*}{ Fenotípicas } & \multirow[b]{2}{*}{ Ambientais } \\
\hline & & & \\
\hline \multicolumn{4}{|l|}{ Peso de 100 sementes com } \\
\hline Teste da primeira contagem & 0,14 & 0,14 & $0,23 * *$ \\
\hline Germinação & $0,22 * *$ & $0,21 * *$ & 0,04 \\
\hline Dormência & $0,37 * *$ & $0,34 * *$ & 0,03 \\
\hline EA com água & $0,27 * *$ & $0,26 * *$ & 0,05 \\
\hline EA com solução salina & $0,31 * *$ & $0,30 * *$ & 0,10 \\
\hline 12 meses a $25^{\circ} \mathrm{C}$ - Germinação & $0,39 * *$ & $0,37 * *$ & $-0,04$ \\
\hline 12 meses a $15^{\circ} \mathrm{C}$ - Germinação & $0,35 * *$ & $0,34 * *$ & 0,05 \\
\hline \multicolumn{4}{|l|}{ Teste da primeira contagem com } \\
\hline Germinação & $0,98 * *$ & $0,96 * *$ & $0,75 * *$ \\
\hline Dormência & $-0,50 * *$ & $-0,47 * *$ & $-0,35 * *$ \\
\hline EA com água & $0,72 * *$ & $0,66 * *$ & 0,01 \\
\hline EA com solução salina & $0,73 * *$ & $0,67 * *$ & $-0,02$ \\
\hline 12 meses a $25^{\circ} \mathrm{C}$ - Germinação & $0,65 * *$ & $0,60 * *$ & $-0,02$ \\
\hline 12 meses a $15^{\circ} \mathrm{C}$ - Germinação & $0,66 * *$ & $0,63 * *$ & 0,13 \\
\hline \multicolumn{4}{|l|}{ Germinação com } \\
\hline Dormência & $-0,35 * *$ & $-0,37 * *$ & $-0,54 * *$ \\
\hline EA com água & $0,80 * *$ & $0,73 * *$ & 0,05 \\
\hline EA com solução salina & $0,83 * *$ & $0,77 * *$ & 0,07 \\
\hline 12 meses a $25^{\circ} \mathrm{C}$ - Germinação & $0,75 * *$ & $0,69 * *$ & $-0,02$ \\
\hline 12 meses a $15^{\circ} \mathrm{C}$ - Germinação & $0,74 * *$ & $0,70 * *$ & $0,23 * *$ \\
\hline \multicolumn{4}{|l|}{ Dormência com } \\
\hline EA com água & $-0,07$ & $-0,08$ & $-0,16$ \\
\hline EA com solução salina & $-0,03$ & $-0,03$ & 0,01 \\
\hline 12 meses a $25^{\circ} \mathrm{C}$ - Germinação & 0,09 & 0,09 & 0,11 \\
\hline 12 meses a $15^{\circ} \mathrm{C}$ - Germinação & 0,03 & 0,02 & $-0,02$ \\
\hline \multicolumn{4}{|l|}{ EA com água com } \\
\hline EA com solução salina & $0,92 * *$ & $0,84 * *$ & $-0,05$ \\
\hline 12 meses a $25^{\circ} \mathrm{C}$ - Germinação & $0,77 * *$ & $0,70 * *$ & $-0,04$ \\
\hline 12 meses a $15^{\circ} \mathrm{C}$ - Germinação & $0,83 * *$ & $0,76 * *$ & $-0,02$ \\
\hline \multicolumn{4}{|l|}{ EA com solução salina com } \\
\hline 12 meses a $25^{\circ} \mathrm{C}$ - Germinação & $0,90 * *$ & $0,84 * *$ & $-0,08$ \\
\hline 12 meses a $15^{\circ} \mathrm{C}$ - Germinação & $0,90 * *$ & $0,85 * *$ & 0,14 \\
\hline \multicolumn{4}{|c|}{12 meses a $25^{\circ} \mathrm{C}$ - Germinação com } \\
\hline 12 meses a $15^{\circ} \mathrm{C}$ - Germinação & $0,95 * *$ & $0,89 * *$ & 0,16 \\
\hline
\end{tabular}

** Significativo em nível de $1 \%$ de probabilidade pelo teste $\mathrm{t}$.

NAKAGAWA, 2012). Isso pode ser comprovado pela inexistência de correlação significativa entre esses caracteres em sementes armazenadas, em todos os períodos de tempo estudados (3, 6, 9 e 12 meses), em ambas as condições de temperaturas testadas.

As correlações genotípicas indicam que, ao selecionar um caracter, haverá ganhos genéticos simultâneos nos outros correlacionados. Assim, pode-se verificar que a massa de cem sementes, a porcentagem de germinação, os testes de primeira contagem de germinação, envelhecimento acelerado com água e com solução salina podem ser utilizados para a seleção de populações de cenoura com sementes de maior vigor, de acordo com todos os testes de vigor realizados. Também se mostraram eficientes na seleção de sementes com maior longevidade, tanto para o armazenamento à temperatura de $25^{\circ} \mathrm{C}$, próxima à média de um ambiente de armazém não controlado, como de $15^{\circ} \mathrm{C}$, que é a temperatura das câmaras frias utilizadas para o armazenamento de 
sementes de olerícolas nas empresas. No entanto, como relatado anteriormente, a correlação genética positiva entre o peso das sementes e a dormência indica que a seleção baseada em peso das sementes não deve ser utilizada.

Assim, os testes de germinação, da primeira contagem de germinação, envelhecimento acelerado com água e com solução salina podem ser usados em programas de melhoramento genético para a seleção de sementes com maior longevidade e vigor, o que favoreceria as empresas de sementes e o produtor. Esses testes são rápidos na seleção da longevidade, possibilitando uma redução considerável de tempo para a seleção dos genótipos, principalmente quando comparados aos 12 meses de armazenamento, pois permitiram essa discriminação entre quatro e 14 dias, dependendo do teste. Adicionalmente, são práticos e econômicos, necessitando somente de materiais, equipamentos e pessoal técnico com treinamento usual de laboratório de sementes (SPÍNOLA et al., 1998; RODO et al., 2000).

As correlações genotípicas, associada às correlações fenotípicas significativas, observadas na tabela 2, permitem que a seleção das progênies geneticamente superiores seja feita com base nas características fenotípicas, passíveis de avaliação visual, que constituem a principal ferramenta de seleção de programas de melhoramento genético tradicionais.

Como a quase totalidade dos caracteres apresentaram alta correlação genética e fenotípica entre si, optou-se pelo caracter germinação das sementes após armazenamento por 12 meses a $25^{\circ} \mathrm{C}$ para os cálculos do ganho por seleção, por ser um parâmetro de longevidade das progênies. Após o armazenamento por 12 meses a $25^{\circ} \mathrm{C}$, a média da germinação (\%) da população original de 50 progênies foi de $66 \%$ (Figura 1). O número de progênies individuais selecionadas para germinação após o armazenamento por 12 meses a $25^{\circ} \mathrm{C}$ foi de 14 , valor que corresponde a $20,8 \%$ das progênies avaliadas. O ganho genético para esse parâmetro foi de $14 \%$ e a germinação após o armazenamento por 12 meses a $25^{\circ} \mathrm{C}$ estimada para a população melhorada foi estimada em $80 \%$.

\section{CONCLUSÃO}

A variabilidade genética dos caracteres avaliados mostrou que o melhoramento genético pode contribuir significativamente para a melhoria da qualidade fisiológica das sementes de cenoura. A seleção baseada na massa de sementes não deve ser utilizada, pois aumentaria a ocorrência de dormência nas sementes da geração seguinte. $O$ teste da primeira contagem, o teste de germinação e de envelhecimento acelerado com água ou solução salina saturada podem ser utilizados para a seleção de populações de cenoura com sementes de maior vigor e longevidade. $\mathrm{O}$ ganho genético estimado para a germinação após o armazenamento por 12 meses a $25^{\circ} \mathrm{C}$ é de $14 \%$.

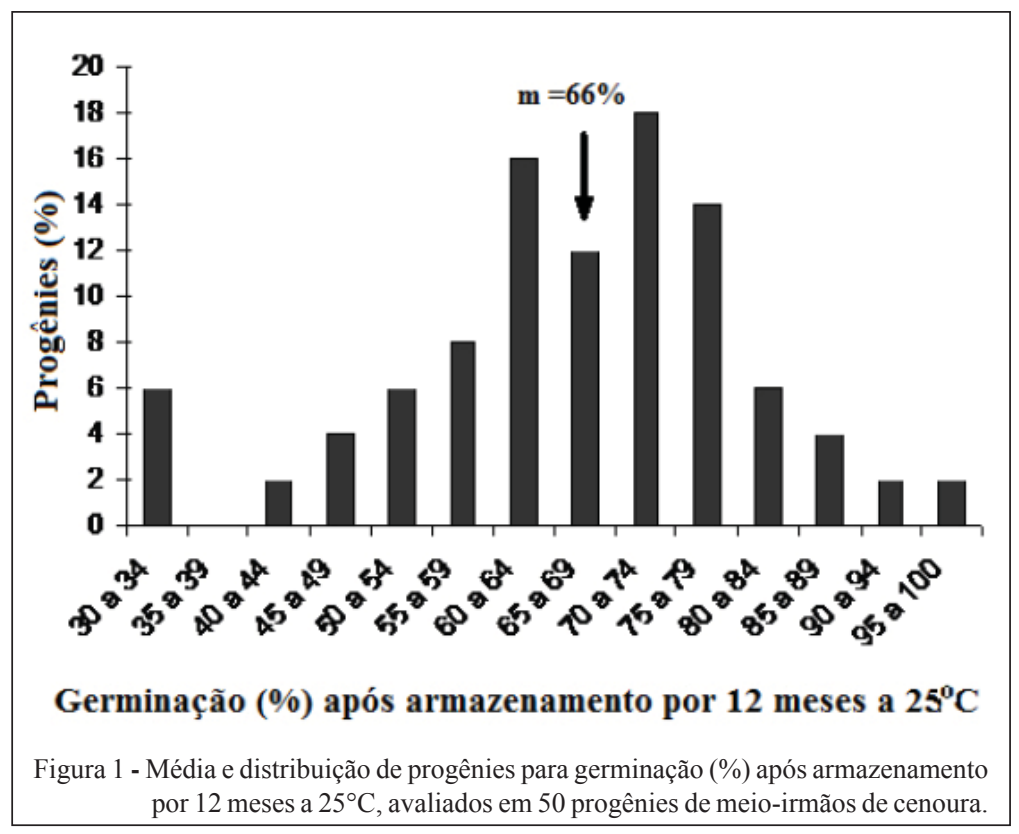

Ciência Rural, v.44, n.5, mai, 2014. 


\section{AGRADECIMENTOS}

À Fundação de Amparo à Pesquisa do Estado de São Paulo (FAPESP) pelo auxílio à pesquisa (Proc. 06 57692-8) e Conselho Nacional de Desenvolvimento Científico e Tecnológico $(\mathrm{CNPq})$ pela bolsa de produtividade em pesquisa do primeiro autor.

\section{REFERENCIAS}

ANDRADE, R.N. et al. Correlação entre testes de vigor em sementes de cenoura armazenadas por diferentes períodos. Pesquisa Agropecuária Gaúcha, v.1, p.153-162, 1995.

BRASIL. Ministério da Agricultura, Pecuária e Abastecimento. Secretaria de Defesa Agropecuária. Regras para análise de sementes. Brasília, 2009. 395p

CARVALHO, N.M.; NAKAGAWA, J. Sementes: ciência tecnologia e produção. 5.ed. Jaboticabal: FUNEP, 2012. 590p.

CRUZ, C.D. Programa genes: aplicativo computacional em genética e estatística. Viçosa: UFV, 1997. 442p.

FREITAS, R.A. Deterioração e armazenamento de sementes de hortaliças. In: NASCIMENTO, W.M. (Ed.). Tecnologia de sementes de hortaliças. Brasília: Embrapa hortaliças, 2009. p.155-184.

HONG, T.D. et al. Survival and vigour of ultra dry seeds after ten years of hermetic storage. Seed Science and Technology, v.33, n.2, p.449-460, 2005

JIANHUA, Z.; McDONALD, M.B. The saturated salt accelerated aging test for small-seed crops. Seed Science and Technology, v.25, n.1, p.123-131, 1997 .

MARCOS FILHO, J.; NOVEMBRE, A.D.L.C. Avaliação do potencial fisiológico de sementes de hortaliças. In: NASCIMENTO, W.M. (Ed.). Tecnologia de sementes de hortaliças. Brasília: Embrapa Hortaliças, 2009. p.185-246.

MARTINS, C.C. et al. Carrot seed size and progenies influence on seed physiological quality and plant productivity performance.
Journal of Food, Agriculture \& Environment, v.11, n.3, p.11431147, 2013. Disponível em: <http://world-food.net/download/ journals/2013-issue_3\&4/2013-issue_3\&4-agriculture/a101.pdf $>$. Acesso em: 05 jan. 2014.

PEREIRA, R.S. et al. Germinação e vigor de sementes de cenoura sob condições de altas temperaturas. Horticultura Brasileira, v.25, n.2, p.215-219, 2007. Disponível em: <http:// www.scielo.br/scielo.php?script $=$ sci arttext\&pid $=\mathrm{S} 0102$ $05362007000200017 \& \operatorname{lng}=\mathrm{en} \& \mathrm{nrm}=\mathrm{iso}>$. Acesso em: 11 ago. 2012. doi:10.1590/S0102-05362007000200017.

RODO, A.B. et al. Metodologia alternativa do teste de envelhecimento acelerado para sementes de cenoura. Scientia Agrícola, v.57, n.2, p.289-292, 2000. Disponível em: <http: //www.scielo.br/scielo.php? script=sci_arttext\&pid $=\mathrm{S} 0103$ $90162000000200015 \& \operatorname{lng}=$ pt\&nrm=iso $>$. Acesso em: 25 abr. 2012. doi:10.1590/S0103-90162000000200015.

SANTOS, V.J. et al. Qualidade fisiológica de sementes de cenoura classificadas por tamanho. Ciência Rural, v.40, n.9, p.1903-1908, 2010. Disponível em: <http://www.scielo.br/scielo. php? script $=$ sci arttext\&pid $=$ S0103-84782010000900008\&lng =pt\&nrm=iso $>$. Acesso em: 25 abr. 2012. doi:10.1590/S010384782010000900008

SILVA, G.O. et al. Estratégias de seleção para germinação de sementes de cenoura em condições de temperaturas elevadas. Revista Ceres, v.58, n.1, p.121-125, 2011. Disponível em: <http:// www.scielo.br/scielo.php?script=sci_arttext\&pid=S0034-737X20 $11000100018 \& \operatorname{lng}=$ pt\&nrm=iso $>$. Acesso em: 25 abr. 2012. doi. $10.1590 / \mathrm{S} 0034-737 \mathrm{X} 2011000100018$

SPÍNOLA, M.C.M. et al. Comparação entre métodos para avaliação do vigor de sementes de cenoura. Revista Brasileira de Sementes, v.20, p. 301-305, 1998.

VIEIRA, J.V. et al. Seleção de progênies de meio-irmãos de cenoura baseada em características de sementes. Horticultura Brasileira, v.23, n.1, p.44-47, 2005. Disponível em: <http:// www.scielo.br/scielo.php? script $=$ sci_arttext\&pid $=$ S0102 05362005000100009\&lng=pt \&nrm=iso $>$. Acesso em: 25 abr. 2012. doi: 10.1590/S0102-05362005000100009. 